\title{
African Trypanosomiasis: Extracellular Vesicles Shed by Trypanosoma brucei brucei Manipulate Host Mononuclear Cells
}

\author{
Tatiana Dias-Guerreiro ${ }^{1,+}{ }^{\dagger}$ Joana Palma-Marques ${ }^{1,+}{ }^{+}$Patrícia Mourata-Gonçalves ${ }^{1}$, Graça Alexandre-Pires ${ }^{2} \oplus$, \\ Ana Valério-Bolas ${ }^{1}{ }^{1}$, Áurea Gabriel ${ }^{1}$ (), Telmo Nunes ${ }^{3}$, Wilson Antunes ${ }^{4}$, Isabel Pereira da Fonseca ${ }^{2}$, \\ Marcelo Sousa-Silva ${ }^{1,5}$ (i) and Gabriela Santos-Gomes ${ }^{1, *(\mathbb{D})}$
}

check for

updates

Citation: Dias-Guerreiro, T.;

Palma-Marques, J.;

Mourata-Gonçalves, P.;

Alexandre-Pires, G.; Valério-Bolas, A.;

Gabriel, Á.; Nunes, T.; Antunes, W.;

Fonseca, I.P.d.; Sousa-Silva, M.; et al.

African Trypanosomiasis:

Extracellular Vesicles Shed by

Trypanosoma brucei brucei Manipulate

Host Mononuclear Cells. Biomedicines

2021, 9, 1056. https://doi.org/

biomedicines 9081056

Academic Editor: Maria Pereira

Received: 16 July 2021

Accepted: 16 August 2021

Published: 20 August 2021

Publisher's Note: MDPI stays neutral with regard to jurisdictional claims in published maps and institutional affiliations.

Copyright: (c) 2021 by the authors. Licensee MDPI, Basel, Switzerland. This article is an open access article distributed under the terms and conditions of the Creative Commons Attribution (CC BY) license (https:// creativecommons.org/licenses/by/ $4.0 /)$.
1 Global Health and Tropical Medicine (GHTM), Instituto de Higiene e Medicina Tropical (IHMT), Universidade Nova de Lisboa (UNL), 1349-008 Lisboa, Portugal; tatiana.rdguerreiro17@gmail.com (T.D.-G.); joanapmarques@ihmt.unl.pt (J.P.-M.); prm.goncalves@campus.fct.unl.pt (P.M.-G.); anasbolas@gmail.com (A.V.-B.); aureamangal@gmail.com (Á.G.); mssilva.ufrn@gmail.com (M.S.-S.)

2 Centro de Investigação Interdisciplinar em Sanidade Animal, Faculdade de Medicina Veterinária, Universidade de Lisboa, 1300-477 Lisboa, Portugal; gpires@fmv.ulisboa.pt (G.A.-P.); ifonseca@fmv.ulisboa.pt (I.P.d.F.)

3 Microscopy Center, Faculty of Sciences, University of Lisbon, Campo Grande, 1749-016 Lisboa, Portugal; telmonunes@hotmail.com

4 Unidade Militar Laboratorial de Defesa Biológica e Química (UMLDBQ), Laboratório de Imagem Nano-Morfológica e Espectroscopia de Raios-X, 1100-471 Lisboa, Portugal; antunez.wdta@gmail.com

5 Centro de Ciências da Saúde, Departamento de Analises Clínicas e Toxicológicas, Universidade Federal do Rio Grande do Norte, Natal 59078-970, Brazil

* Correspondence: santosgomes@ihmt.unl.pt; Tel.: +351-21-365-26-00; Fax: +351-21-363-21-05

+ These two authors contributed equally to this study and are considered co-first authors.

Abstract: African trypanosomiasis or sleeping sickness is a zoonotic disease caused by Trypanosoma brucei, a protozoan parasite transmitted by Glossina spp. (tsetse fly). Parasite introduction into mammal hosts triggers a succession of events, involving both innate and adaptive immunity. Macrophages $(\mathrm{M} \Phi)$ have a key role in innate defence since they are antigen-presenting cells and have a microbicidal function essential for trypanosome clearance. Adaptive immune defence is carried out by lymphocytes, especially by $\mathrm{T}$ cells that promote an integrated immune response. Like mammal cells, T. b. brucei parasites release extracellular vesicles (TbEVs), which carry macromolecules that can be transferred to host cells, transmitting biological information able to manipulate cell immune response. However, the exact role of TbEVs in host immune response remains poorly understood. Thus, the current study examined the effect elicited by TbEVs on M $\Phi$ and T lymphocytes. A combined approach of microscopy, nanoparticle tracking analysis, multiparametric flow cytometry, colourimetric assays and detailed statistical analyses were used to evaluate the influence of TbEVs in mouse mononuclear cells. It was shown that TbEVs can establish direct communication with cells of innate and adaptative immunity. TbEVs induce the differentiation of both M1- and M2-M $\Phi$ and elicit the expansion of $\mathrm{MHCI}^{+}, \mathrm{MHCII}^{+}$and $\mathrm{MHCI}^{+} \mathrm{MHCII}^{+} \mathrm{M} \Phi$ subpopulations. In $\mathrm{T}$ lymphocytes, TbEVs drive the overexpression of cell-surface CD3 and the nuclear factor FoxP3, which lead to the differentiation of regulatory $\mathrm{CD}^{+}$and $\mathrm{CD}^{+}$T cells. Moreover, this study indicates that T. $b$. brucei and TbEVs seem to display opposite but complementary effects in the host, establishing a balance between parasite growth and controlled immune response, at least during the early phase of infection.

Keywords: African trypanosomiasis; Trypanosoma brucei brucei; exosomes; macrophages; T lymphocytes; regulatory T cells

\section{Introduction}

African trypanosomiasis (AT), also known as sleeping sickness in humans and Nagana in cattle, is a vector-borne disease caused by an extracellular kinetoplastida parasite of the Trypanosomatidae family, genus Trypanosoma, and species Trypanosoma brucei, which 
is transmitted by the hematophagous dipteran Glossina spp. (tsetse fly). This parasitosis is considered a neglected tropical disease restricted to the intertropical region of Africa following the geographical distribution of its vector. Parasite transmission to mammals occurs by the inoculation of metacyclic trypomastigotes forms during the insect blood meal.

After being introduced into the host dermis, parasites start to replicate, giving origin to the initial lesion or the inoculation chancre [1,2]. After two or three weeks, the chancre tends to disappear, and the disease can evolve in two distinct successive phases [2]: Phase I or the hemolymphatic stage is characterized by successive waves of invasion of the blood and lymphatic system by trypanosomes, which causes intermittent fever [2,3] and phase II or meningoencephalitis stage, where the typical symptoms of sleeping sickness (dementia, cachexia, coma, and death) may become evident [2-4]. Trypanosome parasites have a dense surface coat constituted by the variant surface glycoprotein (VSG). These immunogenic coats present at the cell surface as homodimers and anchored in the membrane through glycosylphosphatidylinositol constitute the pathogen-associated molecular patterns (PAMPs) that are recognized by pattern-recognition receptors (PPRs) of innate immunity $[2,4]$.

The innate immune response includes macrophages $(M \Phi)$, which can engulf foreign antigens through endocytosis. When soluble parasite factors and VSG interacts with $\mathrm{M} \Phi$, they became classically activated (M1-M $\Phi)$ and synthesize reactive oxygen intermediates $(\mathrm{ROI})$, produce nitric oxide $(\mathrm{NO})$, and release proinflammatory cytokines, as is the case of tumor necrosis factor (TNF)- $\alpha$ and interleukin (IL)-6 (type I cytokines) [2,5]. To reduce inflammation, trypanosome blood forms release some components, such as Trypanosoma brucei-derived kinesin-heavy chain (TbKHC-1) and adenylate cyclase (ADC), which upregulate the IL-10 production that prevents TNF- $\alpha$ expression [6,7], leading to the differentiation of alternative activate $\mathrm{M} \Phi(\mathrm{M} 2-\mathrm{M} \Phi)$ and production of anti-inflammatory cytokines [5]. The inflammatory response is critical for parasite control in the early stage of infection [5] and the switch from M1-M $\Phi$ to $M 2-M \Phi$ seems to occur four weeks after infection when the patient is in the late stage of disease [8].

Together with dendritic cells, M $\Phi$ are antigen-presenting cells (APC), establishing a bridge with adaptive immunity. Parasite antigens complexed with class I molecules of major histocompatibility complex (MHCI) are presented to $\mathrm{CD}^{+} \mathrm{T}$ cells and parasite antigen bound to class II molecules of major histocompatibility (MHCII) complex are recognized by $\mathrm{CD}^{+} \mathrm{T}$ cells. Both $\mathrm{CD}^{+}$and $\mathrm{CD} 8^{+} \mathrm{T}$ cells are crucial in the orchestration of host adaptive immune response against T. $b$. brucei parasites. However, the successive peaks of parasitemia exhibiting specific VSG induce a continuous activation of T cell clones, which leads to cell exhaustion and then to immunosuppression, and consequently impaired parasite control [9].

Like mammal cells, trypanosomes also secrete extracellular vesicles (EV), which comprise nanovesicles that differ in size and carry parasite molecular components, such as proteins, lipids, and nucleic acids [10]. The parasite T. brucei releases EV (TbEVs) that seems to play a role in both parasite-parasite and parasite-host interactions, influencing host immune response [11]. Moreover, TbEVs appear to incorporate different flagellar proteins, acting like virulence factors, and be highly enriched in oligomers, such as tetraspanins (a broadly expressed superfamily of transmembrane glycoproteins), known to be involved in antigen presentation, $\mathrm{T}$ cell signalization and activation, and in MHCI and MHCII generation. Also, it was demonstrated that upon fusion with erythrocytes, these TbEVs are responsible for the removal of red cells from the host bloodstream [12].

For parasite survival in the mammal host and success in being transmitted to the insect vector, ensuring the completion of the T. brucei life cycle, the infected host must develop a balanced immune response able to prevent the host killing and allow parasite replication. Despite all the studies done to understand the immune mechanisms associated with this parasitic disease, the exact role played by TbEVs in host immune response is still evasive. Thus, this work explores the effect of TbEVs in the immune activation of mouse mononuclear cells. 


\section{Materials and Methods}

\subsection{Experimental Design}

To explore the effect of TbEVs on host immune response an experimental design comprising three main steps was established. The first step aims to examine the shape, size, and density of purified TbEVs using electron microscopy and nanoparticle tracking analysis. In the second step, the aim was to investigate the innate activity of $M \Phi$ when stimulated by TbEVs, including their microbicide and antigenic presentation potential, and the last goal step aims to assess the differentiation of $\mathrm{T}$ cell subsets related to effector and regulatory adaptive immune response.

Mouse $M \Phi$-like cells were exposed to T. $b$. brucei trypomastigotes and stimulated by TbEVS and BALB/c mice peripheral blood mononuclear cells (PBMC) were exposed to T. b. brucei trypomastigotes and stimulated by TbEVS and parasite antigen (Ag). Type I and type II M $\Phi$ activity was analyzed by NO and urea production using colourimetric assays. The potential of $\mathrm{M} \Phi$ to present parasite antigens to lymphocytes was indirectly evaluated by the expression and density of surface molecules MHCI and MHCII by flow cytometry. T lymphocyte subsets were immunophenotyped by flow cytometry through surface expression and density of CD3 and CD25 molecules and intracellular expression of FoxP3. In parallel, resting cells, M $\Phi$ stimulate by phorbol myristate acetate (PMA) and PBMC stimulated by concanavalin A (ConA) were also evaluated. Furthermore, obtained data were subject to statistical procedures.

\section{2. $B A L B / c$ Mice}

Six to eight-week-old male BALB/c Mus musculus mice were purchased from the Instituto Gulbenkian de Ciências (IGC, Lisbon, Portugal) and maintained in the IHMT animal facility, in sterile cabinets with sterile food and water ad libitum. Mice were used to recover Trypanosome blood forms and to isolate PBMC. The animals were handled according to the Portuguese National Authority for Animal Health (Ref. 0421/000/000/2020, 23 September 2020, DGAV—Direção Geral de Alimentação e Veterinária), in conformity with the institutional guidelines and the experiments performed in compliance with Portuguese law (Decree-Law 113/2013), EU requirements (2010/63/EU), and following the recommendations of the Federation of European Laboratory Animal Science Associations (FELASA).

\subsection{Trypanosoma brucei brucei Parasites}

Peripheral blood of BALB/c mice infected with T. brucei brucei strain G.V.R. 35 was collected (Supplementary Videos S1 and S2) and treated with ammonium-chloride-potassium lysis buffer. Trypanosoma blood forms were then purified using diethyl aminoethyl (DEAE)cellulose columns [13] and maintained in Schneider Drosophila medium (Sigma-Aldrich, Hamburg, Germany) supplemented with $10 \%(v / v)$ of heat-inactivated fetal bovine serum (hiFBS) free of extracellular vesicles (FBS-exofree, Thermo Fisher Scientific, Waltham, MA, USA) at $24^{\circ} \mathrm{C}$. Parasite morphology and motility were checked every day by direct microscopy and, parasite topography was evaluated by scanning electron microscopy (SEM, SEM-UR- LBDB Hitachi SU8010 High-Technologies Corporation, Ibaraki, Japan). TbEVs were purified from the supernatant of cultures exhibiting motile trypomastigotes.

\subsection{T. b. brucei Extracellular Nanovesicles and Parasite Crude Antigen}

Trypomastigotes harvested from cultures by centrifugation at $2000 \times \mathrm{g}$ for $10 \mathrm{~min}$ at $4{ }^{\circ} \mathrm{C}$ were used to produce parasite antigen $(\mathrm{Ag})$, and TbEVs were obtained from culture supernatants. Parasites were washed twice in phosphate-buffered saline (PBS) $2 \mathrm{mM}$ ethylenediaminetetraacetic acid (EDTA), resuspended in PBS, and then disrupted by eight freeze-thawing cycles ranging from $-20{ }^{\circ} \mathrm{C}$ to room temperature. After centrifugation, protein content $\left(\mathrm{mg} \cdot \mathrm{mL}^{-1}\right)$ was determined using a Nanodrop 1000 spectrophotometer (Thermo Scientific, Waltham, MA, USA), and Ag was preserved at $-20^{\circ} \mathrm{C}$. Supernatants of trypomastigote culture incubated for $48 \mathrm{~h}$ were filtered through $0.2 \mathrm{~mm}$ syringe filters 
(VWR International, Radnor, PE, USA), and TbEVs were purified using Exosome Spin Columns (Invitrogen, Waltham, MA, USA) according to the manufacturer's instructions. Isolated TbEVs were examined by SEM, single particle size and concentration analyzed by Nanoparticle Tracking Analysis (NanoSight NTA 3.2), and protein content was estimated by spectrophotometry.

\subsection{Morphology of T. b. brucei and Parasite Extracellular Vesicles}

Cultured T. b. brucei parasites deposited on glass slides were observed under an optical microscope to evaluate parasite motility and morphology. The topography of TbEVs and morphology of cultured-derived parasites were examined by SEM.

Round glass coverslips were immerged into poly-D-lysine (Sigma-Aldrich, Burlington, MA, USA) overnight to increase adherence and later placed in a 24-well plate. Then parasites were allowed to adhere to the coverslips and were fixed with PBS $4 \%$ paraformaldehyde (Merck, Rahway, NJ, USA) for $30 \mathrm{~min}$ at $4{ }^{\circ} \mathrm{C}$. Coverslips were rinsed three times with distilled water, treated with $0.5 \%$ osmium tetroxide (Sigma-Aldrich), and washed again. Then, plates were incubated with a fixative solution of $1 \%$ tannic acid (Sigma-Aldrich) for $30 \mathrm{~min}$. TbEVs were fixed to coverslips with $2.5 \%$ glutaraldehyde, $0.1 \mathrm{M}$ sodium cacodylate buffer, $\mathrm{pH} 7.4$ for $2 \mathrm{~h}$ at $4{ }^{\circ} \mathrm{C}$. Afterwards, both parasites- and TbEV-coverslips were washed and then dehydrated by sequential addition of 30\%,50\%, 70\%, 80\%, and 90\% ethanol for 5 min each. Coverslips were immersed in 100\% ethanol and then treated with hexamethyldisilazane solvent (Sigma-Aldrich), coated with gold-palladium, mounted on stubs to be observed under an ultra-high resolution scanning electron microscope. The surface area and perimeter of TbEVs were quantified from acquired images using Image J software.

\subsection{Macrophage Cell Line and Primary Mononuclear Cells}

PMBC were isolated from healthy (non-infected) BALB/c mice by density gradient [14]. Briefly, cells at Hystopaque-1077 (Sigma-Aldrich) and plasma interface were removed and washed three times in PBS by centrifugation at $370 \times g$ for $10 \mathrm{~min}$ at $4{ }^{\circ} \mathrm{C}$. Then, the supernatant was discarded and the PMBC-containing pellet resuspended in PBS. Cell viability was evaluated using the trypan blue staining method and cell concentration estimated in a Neubauer-counting chamber by direct microscopy.

A macrophage (MФ)-like cell line (P388D1, ATCC, Bird Park, Hawaii, USA) previously isolated from a mouse lymphoma was expanded in RPMI-1640 (Lonza, Basel, Switzerland) supplemented with 10\% $(v / v)$ of hiFBS, $2 \mathrm{mM}$ L-glutamine (Merck) (complete RPMI medium) at $37^{\circ} \mathrm{C}$ in a humidified atmosphere with $5 \% \mathrm{CO}_{2}$.

\subsection{Stimulation of Macrophages and PBMC by TbEVS}

$\mathrm{M} \Phi\left(2 \times 10^{6}\right.$ cells per well $)$ and PBMC $\left(1 \times 10^{5}\right.$ cells per well $)$ were plated in a sterile 96-well plate with complete RPMI medium and separately exposed to viable parasites (3 parasites per cell) and stimulated with TbEVs $\left(10 \mu \mathrm{g} \cdot \mathrm{mL}^{-1}\right)$. PBMC also was stimulated by T. $b$. brucei soluble antigen $\left(10 \mu \mathrm{g} \cdot \mathrm{mL}^{-1}\right)$. M $\Phi$ plates were incubated for $24 \mathrm{~h}$ and PBMC plates for $72 \mathrm{~h}$ at $37{ }^{\circ} \mathrm{C}$ in a humidified atmosphere with $5 \% \mathrm{CO}_{2}$. In parallel, unstimulated cells, used as the negative control, and PMA (Promega, Madison, WI, USA) stimulated M $\Phi$ and ConA (Sigma-Aldrich)-stimulated lymphocytes, used as the positive controls, were also incubated.

\subsection{Nitric Oxide and Urea Production by Macrophages}

Supernatants of $\mathrm{M} \Phi$ exposed to viable parasites, stimulated by TbEVs and PMA, and non-stimulate (resting $M \Phi$ ) were collected and used for quantification of urea by the commercial kit QuantiChrom ${ }^{\mathrm{TM}}$ Urea Assay Kit-DIUR-100 (BioAssay System, Hayward, CA, USA) and the indirect measurement of $\mathrm{NO}$ levels through the detection of $\mathrm{NO}_{2}{ }^{-}$and $\mathrm{NO}_{3}{ }^{-}$using the Nitrate/Nitrite Colorimetric Assay (Abnova, Walnut, CA, USA). Both assays were performed according to the manufacturer's instructions. 


\subsection{Macrophage and Lymphocyte Immunophenotyping}

Cells (M $\Phi$ and PBMC) exposed to motile parasites and stimulated were harvested from plates and washed with PBS. M $\Phi$ were labelled with mouse anti-MHCI $(\mathrm{H}-2 \mathrm{~Kb})$ monoclonal antibody FITC directly conjugated and mouse anti-MHCII (I-A/I-E) monoclonal antibody PE directly conjugated (BioLegend, San Diego, CA, USA).

PBMC were resuspended in PBS $0.5 \%$ hiFBS $2 \mathrm{mM}$ EDTA and were added magnetic microbeads coated with mouse anti-CD8a (Ly-2) monoclonal antibody (Miltenyi Biotec, Bergisch Gladbach, Germany). Cells were incubated for $15 \mathrm{~min}$ at $4{ }^{\circ} \mathrm{C}$ protected from light and then washed. $\mathrm{CD} 8^{+}$cells were sorted by positive selection, using a MACS ${ }^{\circledR}$ system (Miltenyi Biotec) while $\mathrm{CD}^{-}$cells were eluted.

Sorted $\mathrm{CD}^{+}$and $\mathrm{CD} 8^{-}$cell fractions were washed with PBS $2 \%$ hiFBS $0.01 \% \mathrm{NaN}_{3}$ and incubated for $30 \mathrm{~min}$ with mouse anti-CD3 monoclonal antibody FITC-directly conjugated and mouse anti-CD25 monoclonal antibody PerCP-cy5.5 directly conjugated (BioLegend). After two washes in PBS, cell suspensions were fixed with PBS $2 \%$ formaldehyde. Cells were then resuspended in permeabilization buffer (PBS 1\% FBS, 0.1\% NaN3, 0.5\% Triton-X, pH 7.4-7.6) and incubated for $20 \mathrm{~min}$, washed and labelled with mouse anti-FoxP3 monoclonal antibody PE directly conjugated (BioLegend).

Cell acquisition was performed in a 4-colour flow cytometer (BD FACSCalibur, BD Biosciences, USA) and data were analyzed using Flowjo V10 (Tree Star Inc., Ashland, OR, USA). FSC-H vs. SSC-H gate was used to remove debris and pyknotic cells in the lower left quadrant of the plot as well as the large (off-scale) debris found in the upper right quadrant. Singlet gate was used to define the non-clumping cells based on pulse geometry FSC-H vs. FSC-A, eliminating the doublets. $\mathrm{CD}^{+}, \mathrm{CD}^{2} 5^{+}$, and $\mathrm{FoxP}^{+}$cell subsets were defined using fluorescence minus one control (FMOs).

To validate the composition of magnetically separated cell fractions, samples of unprimed $\mathrm{CD}^{+}$and $\mathrm{CD}^{-}$cell fractions were stained with the anti-CD3 monoclonal antibody and anti-CD4 monoclonal antibody PerCp directly conjugated (BioLegend) and evaluated by flow cytometry. In $\mathrm{CD}^{+}$cell fraction, less than $20 \%$ of cells presented a $\mathrm{CD}^{+} \mathrm{CD}^{-}$ phenotype, indicating that this cell fraction mainly was constituted by $\mathrm{CD}^{+} \mathrm{T}$ cells and in the CD8 ${ }^{-}$cell fraction $\approx 85 \%$ of the cells evidenced a $\mathrm{CD}^{+} \mathrm{CD} 4^{+}$phenotype, which is consistent with the predominance of $\mathrm{CD}^{+} \mathrm{T}$ cells.

\subsection{Statistical Analysis}

Data analysis was performed using GraphPad Prism version 8 (GraphPad Software, San Diego, CA, USA). After verification by a Kolmogorov-Smirnov test that the data of the current study do not evidence a normal distribution, significant differences were determined using the non-parametric Wilcoxon matched-pair signed-rank test. A 5\% $(p<0.05)$ significance level was used to evaluate statistical significance. The surface and perimeter of TbEVs are represented by violin plots (median, interquartile ranges and distribution). Cell results of at least three independent experiments evaluated in triplicate are expressed by whiskered box-plots, indicating the median, maximum and minimum values or by graph bars (mean and standard error). The relative importance of TbEVs in cell activity was assessed by the principal component analysis (PCA) of exploratory multivariate statistical analysis, using Past4.03 (Natural History Museum, University of Oslo, Oslo, Norway). PCA analysis organizes data in principal components, which can be visualized graphically with a minimal loss of information, making visible the differences between the activation of cells exposed to T. b. brucei parasites, TbEVs and Ag stimulated cells. K-means cluster analysis also was used for cluster validation.

\section{Results}

\subsection{T. b. brucei Trypomastigote Forms Release Extracellular Vesicles}

Cultured-derived T. b. brucei parasites observed by direct microscopy and by scanning electronic microscopy showed an elongated body, a flagellum (Figure 1A), and an undulating membrane (Figure 1B), which are recognised as the morphological characteristic of the 
trypomastigote form. Besides, cultured-derived parasite exhibited nanovesicles that seems to bud from the cell surface and flagellum (Figure 2A,B).
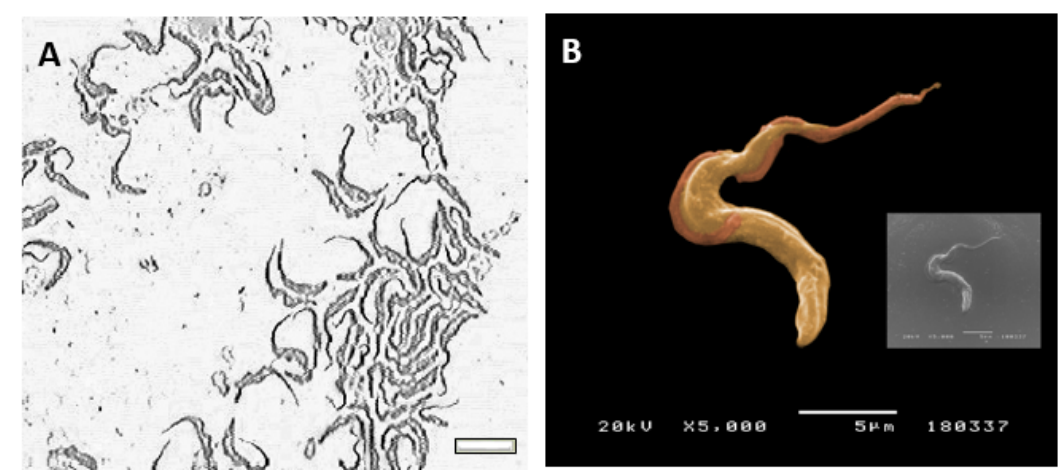

Figure 1. Trypomastigote forms of Trypanosoma brucei brucei. Culture-derived parasites were morphologically evaluated under an inverted light microscope (A, size bar $-10 \mu \mathrm{m}, \times 400$ magnification) and after metalization topographically analyzed by SEM (B). Image B was artificially coloured using the GIMP2.10.0 software.

A
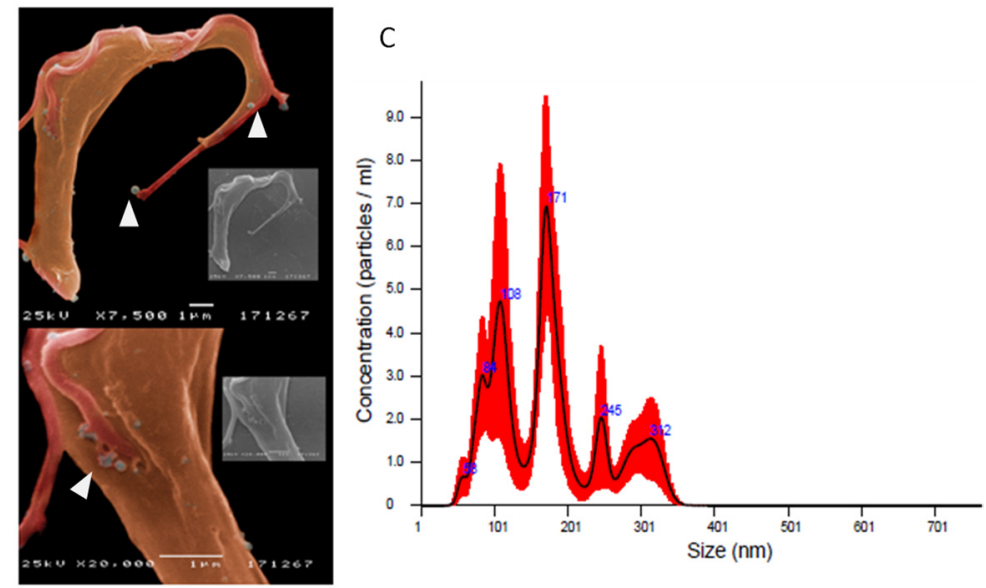

Figure 2. Release of extracellular nanovesicles by T. b. brucei and size and concentration of purified TbEVs. Representative images (A,B) of culture-derived parasites shedding nanovesicles (arrowheads) were acquired by SEM. TbEVs harvested from supernatants of T. $b$. brucei cultures were analyzed by NTA (C). Mean values (blue) + SD (red) are represented by average finite track length adjustment (FTLA) concentration/size graph.

Suspension of purified nanovesicles derived from trypomastigote forms of T. b. brucei evidenced a mean protein concentration of $5.107 \mu \mathrm{g} \cdot \mathrm{mL}^{-1}(\approx 35.28)$ and NTA analysis revealed that the size of TbEVs was within a range of $50 \mathrm{~nm}$ and $350 \mathrm{~nm}$.

Two peaks of higher concentration of TbEVs with sizes around 100 and $170 \mathrm{~nm}$ were detected, while TbEVs bigger than $200 \mathrm{~nm}$ seem to be rare (Figure 2C). The topographic analysis place in evidence vesicles with a spherical shape and a smooth surface (Figure 3A), with perimeter ranging between 335 and $3311 \mathrm{~nm}$ (mean $1634 \mathrm{~nm} \pm 94.07$ ) (Figure 3B) and surface area between 9 and $872 \mathrm{~nm}$ (mean $255.2 \mathrm{~nm} \pm 25.40$ ) (Figure 3C). These data also indicate that cultured-derived T. b. brucei parasites release two main classes of TbEVs: small TbEVs (with perimeter and surface area around $65 \mathrm{~nm}$ and $905 \mathrm{~nm}$, respectively) and large TbEVs (with perimeter and surface area around $346 \mathrm{~nm}$ and $2088 \mathrm{~nm}$, respectively). 

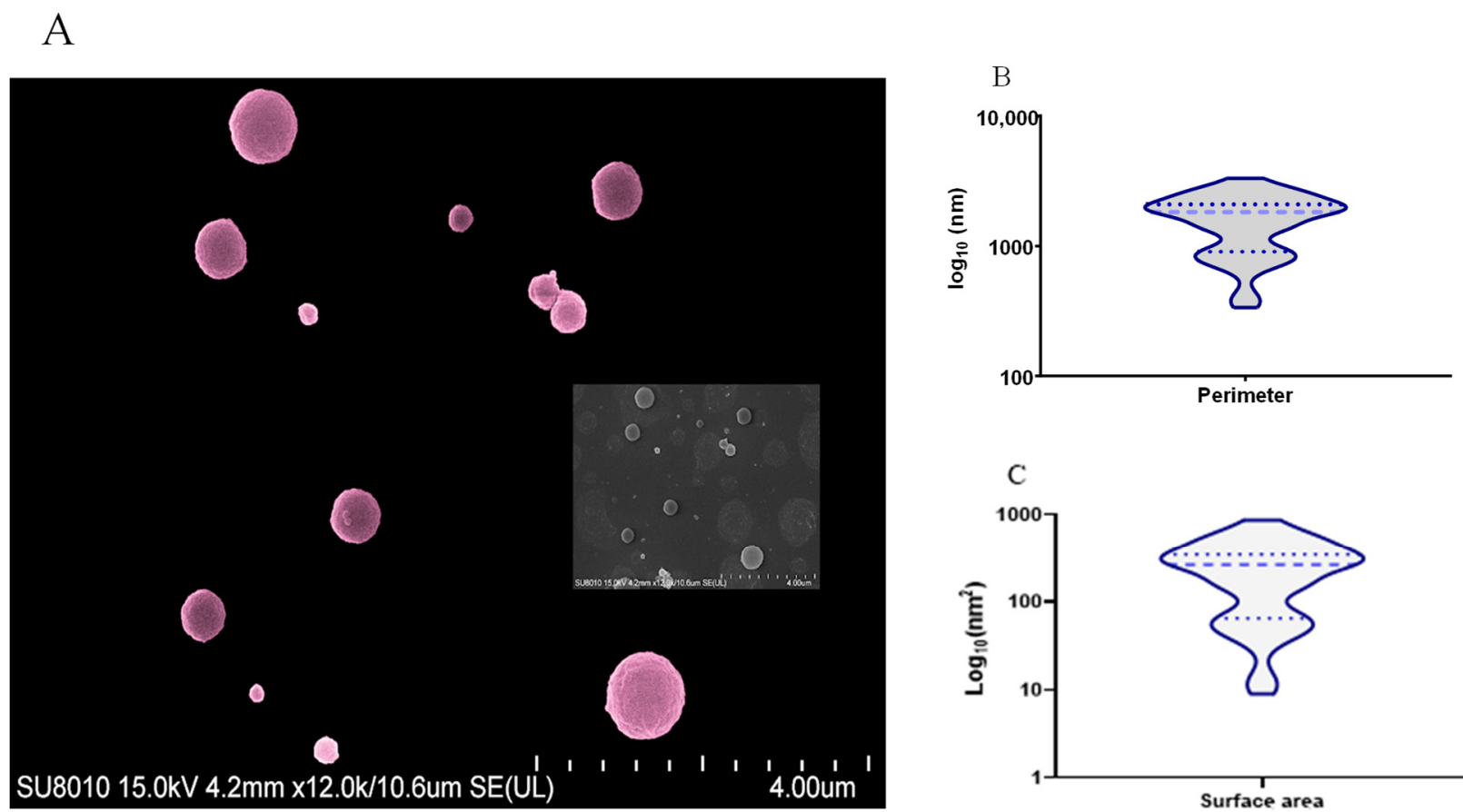

Figure 3. Topography and dimensions of T. $b$. brucei extracellular nanovesicles. TbEVs purified from culture-derived parasites were analyzed by SEM and images were acquired. A representative image of TbEVs (A) artificially coloured, using the GIMP2.10.0 software is shown. Perimeter (B) and surface area (C) of TbEVs estimated by Image J are represented by violin plots, indicating median (thick blue bars), interquartile range (blue dots) and distribution.

\subsection{T. b. brucei and TbEVs Induced Mouse M $\Phi$ to Produce NO and Urea}

M $\Phi$ activity after stimulation with TbEVs was examined by the ability of cells to metabolize arginine (Figure 4).
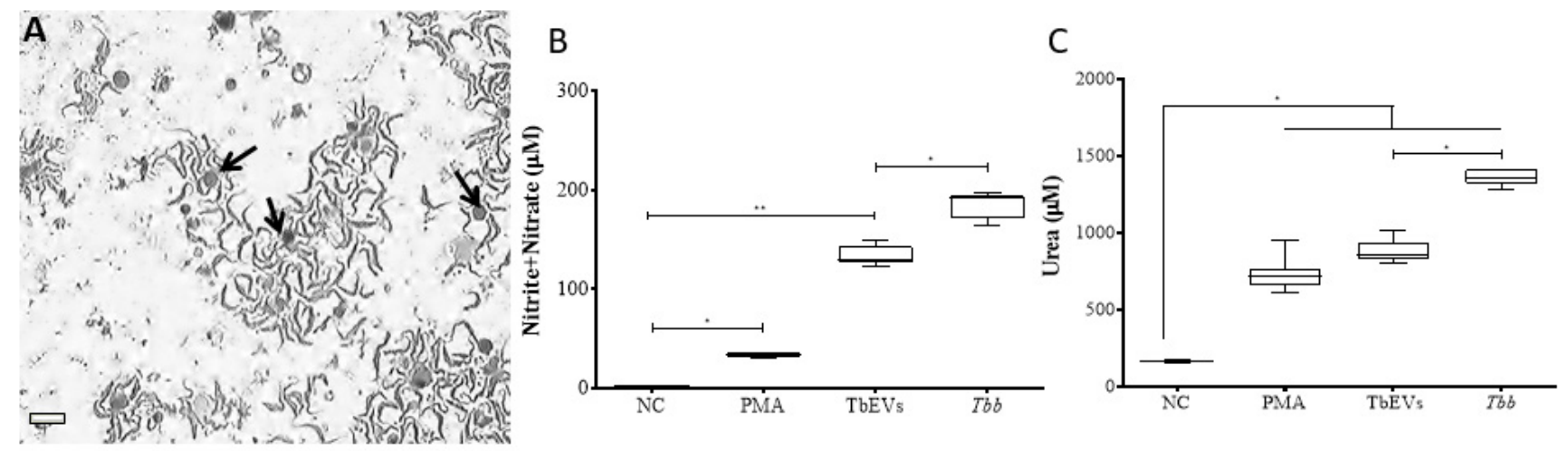

Figure 4. Production of nitric oxide and urea by macrophages exposed to TbEVs. M $\Phi$ (arrows) exposed to trypomastigote forms were observed under an inverted light microscope ((A), size bar-20 $\mu \mathrm{m}, \times 100$ magnification). NO (B) and urea (C) production were evaluated in $\mathrm{M} \Phi$ exposed to T. b. brucei (Tbb) parasites, in $\mathrm{M} \Phi$ stimulated by TbEVs and PMA, and in resting-MФ (negative control, NC). Results of three independent experiments $(n=12)$ and two replicates per sample are represented by whiskered box plots, including median, minimum, and maximum values. The non-parametric Wilcoxon matched-pairs signed-rank test was used for statistical comparisons $(p<0.05) .{ }^{*}(p<0.05)$ and ${ }^{* *}(p<0.01)$ indicate statistical significance.

Resting-M $\Phi$ incubated for $24 \mathrm{~h}$ (negative control) exhibited a residual NO synthesis (Figure 4B). However, after PMA-stimulation (positive control), cells revealed a significant NO increase $(p=0.0078)$, thus confirming the viability and functionality of these cells that could transform arginase into NO through the enzymatic activity of NOS2. M $\Phi$ 
stimulated by TbEVs ( $p=0.0313$ ) or T. b. brucei parasites $(p=0.0078)$ (Figure $4 \mathrm{~A})$ showed significant increases in NO levels when compared with resting МФ. МФ exposed to parasites exhibited the higher NO production that was significantly different from TbEVs exposed-M $\Phi(p=0.0313)$.

In resting-M $\Phi$ were detected low levels of urea (Figure 4C). However, PMA stimulated cells showed a significant increase in urea production $(p=0.0156)$, indicating that these cells can convert arginine into urea through arginase enzymatic activity. M $\Phi$ stimulated by TbEVs or exposed to parasites also exhibited significant high levels of urea when compared with resting-M $\Phi(p=0.0313)$.

Although both $T$. $b$. brucei parasites and TbEVs promote mouse $\mathrm{M} \Phi$ to produce NO and release urea, parasites elicit the highest secretion.

\subsection{TbEVs Direct the Differentiation of $\mathrm{MHCI}^{+}, \mathrm{MHCII}^{+}$and $\mathrm{MHCI}^{+} \mathrm{MHCII}$ Macrophage Subsets}

To indirectly evaluate the possible presentation of parasite antigens by mouse $M \Phi$, the expression of MHC molecules by M $\Phi$ exposed to TbEVs for $24 \mathrm{~h}$ and the frequency of $\mathrm{MHCI}^{+}$ and $\mathrm{MHCII}^{+} \mathrm{M} \Phi$ subsets were analyzed by flow cytometry (Supplementary Figure S1 and Figure 5).

A

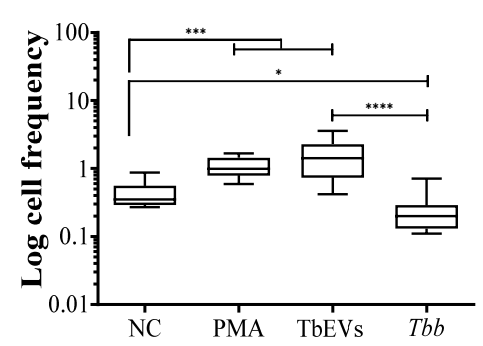

B

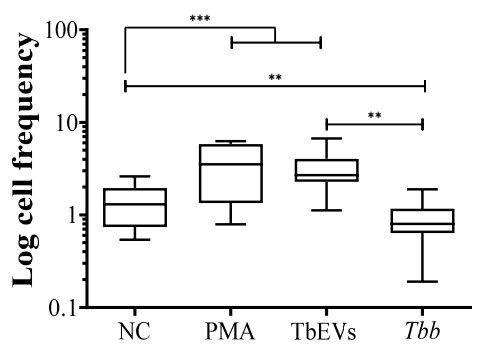

C

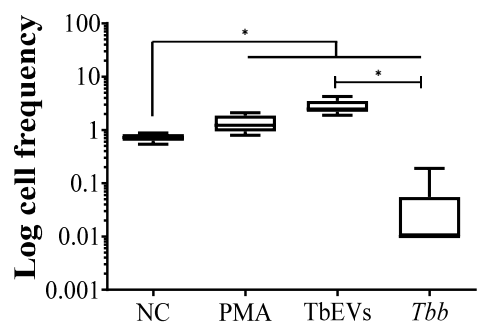

Figure 5. $\mathrm{MHCI}$ and MHCII surface expression by $\mathrm{M} \Phi$ exposed to TbEVs. After $24 \mathrm{~h}$ of incubation, the frequency of $\mathrm{MHCI}^{+}$(A), $\mathrm{MHCII}^{+}$(B), and $\mathrm{MHCI}^{+} \mathrm{MHCII}^{+}$cells (C) was evaluated in $\mathrm{M} \Phi$ exposed to T. b. brucei (Tbb) parasites, in $\mathrm{M} \Phi$ stimulated by TbEVs and PMA, and in resting-M $\Phi$ (negative control, NC). Results of at least three independent experiments $(n=32)$ and at two replicates per sample are represented by whisker box-plot, median, minimum, and maximum values. The non-parametric Wilcoxon matched-pairs signed-rank test was used for statistical comparisons. ${ }^{*}(p<0.05),{ }^{* *}(p<0.01)$, $* * *(p<0.001)$, and $* * * *(p<0.0001)$ indicate statistically significant values.

A significant high frequency of $\mathrm{MHCI}^{+}$(Figure 5A), $\mathrm{MHCII}^{+}(p=0.0001)$ (Figure 5B), and $\mathrm{MHCI}^{+} \mathrm{MHCII}^{+} \mathrm{M} \Phi(p=0.0313)$ was observed in cells stimulated by PMA (Figure $5 \mathrm{C}$ ) when compared with resting cells. $\mathrm{MHCI}^{+} \mathrm{M} \Phi(p=0.01)$ and $\mathrm{MHCII}^{+} \mathrm{M} \Phi(p=0.0039)$ subsets were inhibited after T. $b$. brucei exposure. On the other hand, TbEVs elicited a significantly high expression of $\mathrm{MHCI}^{+}(p=0.0003)$ and $\mathrm{MHCII}^{+} \mathrm{M} \Phi(p=0.0004)$ in comparison to resting cells and cells exposed to parasites $\left(p_{\mathrm{MHCI}^{+}} \mathrm{M \Phi}^{+}<0.0001, p_{\mathrm{MHCII}}{ }^{+}\right.$ $\mathrm{M} \Phi=0.0039$ ).

TbEVs seemed to be responsible for a significative expansion of $\mathrm{MHCI}^{+} \mathrm{MHCII}^{+} \mathrm{M} \Phi$ subset $(p=0.0313$ ) (Figure 5C). Also, in this case, the exposure to parasites caused a significant reduction of this cell subpopulation when comparing with resting-M $\Phi$ and TbEVs stimulated M $\Phi(p=0.0313)$.

When analyzing the levels of fluorescence intensity, no differences were observed between resting-M $\Phi, M \Phi$ exposed to parasites and TbEVS stimulated $M \Phi$. Only PMAstimulated M $\Phi$ evidence a considerable augment of MHCI $(p=0.0313)$.

Altogether the results indicated that TbEVs enhance the expression of MHCII class I and class II in $M \Phi$, favouring antigen presentation, but did not increase the surface density of these molecules on the cell surface. On the other hand, T. b. brucei parasites promote 
a reduction of $\mathrm{MHCI}^{+}, \mathrm{MHCII}^{+}$and $\mathrm{MHCI}^{+} \mathrm{MHCII}^{+} \mathrm{M} \Phi$ subsets, possible avoiding the antigen presentation and activation of cytotoxic and helper $\mathrm{T}$ cells.

\subsection{TbEVs Promoted Specific Mouse Macrophage Activation}

To identify correlations between the influence of TbEVs and T. $b$. brucei parasites on mouse M $\Phi$, data were analysed by PCA. This statistical analysis indicated that the overall influence of TbEVs and PMA on MФ activity is correlated (Figure 6A). On contrary, T. b. brucei effects on mouse $\mathrm{M} \Phi$ were distinct from TbEVs and resting-M $\Phi$. These results were confirmed by cluster analysis, which aggregates in the same cluster (cluster 3 ) the effects of TbEVs and PMA on M $\Phi$. M $\Phi$ activity caused by parasite exposure was found through clusters 2 and 3, with most of the effects in cluster 2 whereas resting-M $\Phi$ is mainly localized in cluster 1 (Figure 6B).

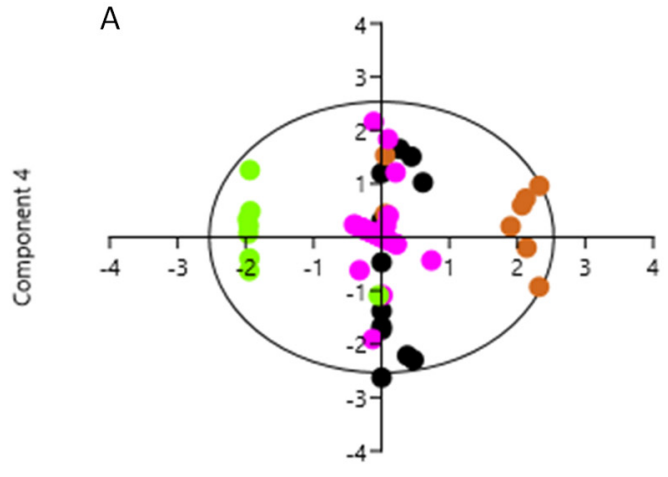

Component 1
B

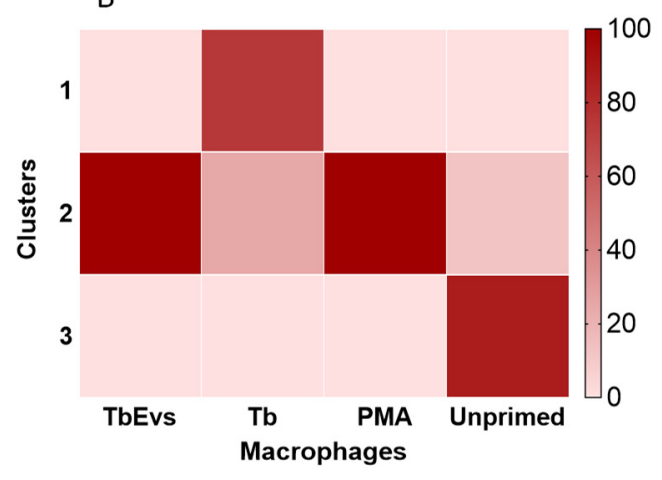

Figure 6. Influence of TbbEVs on mice macrophages. The relationship between the effect of TbbEVs (black dots), PMA (positive control, pink dots), and T. b. brucei parasites (brown dots) in MØ, including urea and NO production and density of MHCI and MHCII, is represented by a variable correlation plot (A). Resting MØ (negative control) are indicated by green dots. Cluster distribution of the effect TbEVs, PMA, and parasites ( $\mathrm{Tb}$ ) in MØ compared with resting cells (NC) are represented by heat map (B).

Therefore, this analysis highlights that TbEVs activation of rodent $M \Phi$ can be different from cell activation induced by T. b. brucei.

3.5. TbEVs Favored the Differentiation of $\mathrm{CD}^{+} \mathrm{T}$ Cells and Increment the Surface Expression of CD3 Molecules

The frequency of $\mathrm{CD}^{+}$cells (Figure 7) and expression level of $\mathrm{CD} 3$ molecules were examined in mononuclear blood cells exposed to parasites or stimulated by TbEVs or parasite Ag (Supplementary Figure S2).

In both $\mathrm{CD}^{+}$(Figure 7A) and CD8 ${ }^{+}$(Figure 7B) cell fractions, the frequency of $\mathrm{CD}^{+}$ cells were significantly lower in cells exposed to T. b. brucei in comparison to unprimed cells $(p=0.0078)$. However, ConA stimulation caused a significant increase in $\mathrm{CD}^{+}$ cells in both cell fractions $(p=0.0078)$. In both cell fractions, cells exposed to parasites were also statistically different from TbEVs and Ag stimulated cells $(p=0.0313)$. TbEVs were responsible for a significant increase of $\mathrm{CD}^{+}$cell subset in the $\mathrm{CD} 4^{+}$cell fraction $(p=0.0078)$ in comparison with unprimed and parasite exposed cells.

The fluorescence intensity of CD3-labelled cells in both cell fractions significantly increased ( $p=0.0313$ ) in Ag and TbEVs stimulated PBMC when compared to unprimed cells. Stimulation by ConA also induced a significant increase $(p=0.0313)$ in CD3-fluorescence intensity of $\mathrm{CD}^{+}$cell fraction. On the other hand, when compared to unprimed cells and TbEVs and Ag-stimulated cells, exposure to T. b. brucei cultured-derived parasites weakened CD3 fluorescence in $\mathrm{CD}^{+}$and $\mathrm{CD}^{+}$cell fractions $(p=0.0313)$.

Altogether, these results indicated that TbEVs stimulation seemed to trigger the expansion of the $\mathrm{CD}^{+}$(CD3hi) $\mathrm{T}$ cell subset and induce the expression of $\mathrm{CD} 3$ molecules 
on $\mathrm{CD}^{+} \mathrm{T}$ cells. In contrast, T. b. brucei parasites impaired the differentiation of $\mathrm{CD}^{+}$and $\mathrm{CD}^{+} \mathrm{T}$ cells and promoted the down expression of $\mathrm{CD} 3$ molecules at the cell surface.

A

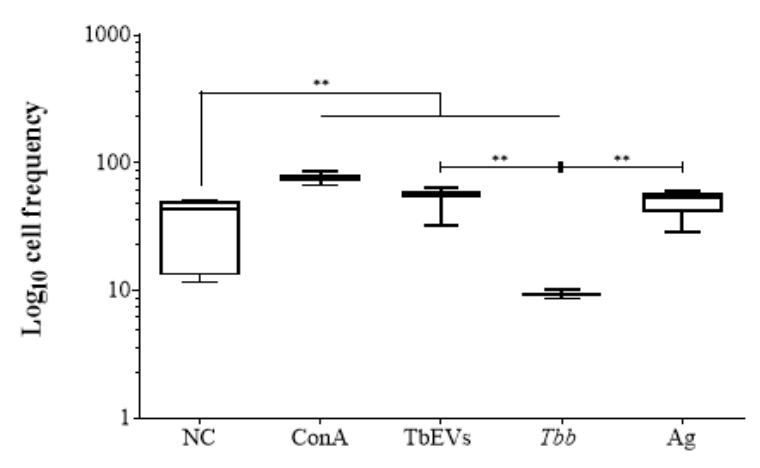

B

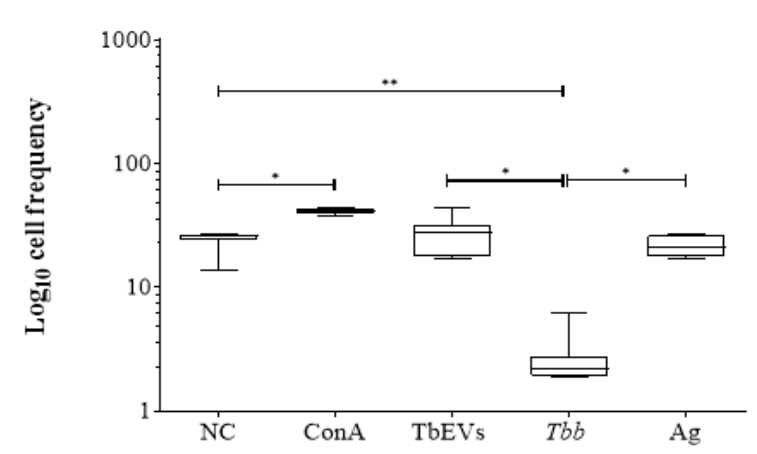

Figure 7. Frequency of $\mathrm{CD}^{+}$cells after exposure of mononuclear cells to TbEVs. $\mathrm{CD} 4^{+}(\mathbf{A})$ and $\mathrm{CD} 8^{+}(\mathbf{B})$ cell fractions exposed to T. b. brucei parasites (Tbb), stimulated by parasite antigen (Ag), TbEVs, and ConA, and unprimed cells (negative control, NC) were labelled with CD3-monoclonal antibody and evaluated by flow cytometry. Results of at least three independent experiments $(n=20)$ performed in duplicate are represented by whiskered box-plot, median, minimum, and maximum values. The non-parametric Wilcoxon matched-pair signed-rank test was used for statistical comparisons. * $(p<0.05)$ and ${ }^{* *}(p<0.01)$ indicate significant differences.

\subsection{TbEVs Led the Expansion of Regulatory $\mathrm{CD} 4^{+} \mathrm{T}$ Cells and FoxP $3^{+} \mathrm{CD} 4^{+} \mathrm{T}$ Cell Subset and Enhanced Surface $\mathrm{CD}_{2} 5^{+}$and Intracellular FoxP3 ${ }^{+}$Molecules}

To assess the effect of TbEVs on $\mathrm{CD} 4^{+}$and $\mathrm{CD} 8^{+} \mathrm{T}$ cell subsets, mononuclear blood cells were exposed to cultured parasites and stimulated by TbEVs or parasite Ag. The frequency of $\mathrm{CD}^{+} \mathrm{T}$ cells expressing CD25 (Figure 8) molecules was evaluated as well as the density of CD25 molecules on the cell surface and intracellular FoxP3 molecules on stimulated cells. Since parasite-exposed cells evidence a low frequency of $\mathrm{CD}^{+}$cells only expression and density CD25 were examined.

T. b. brucei parasites induced a significant expansion of the $\mathrm{CD}^{+} \mathrm{T}$ cell subset expressing CD25 comparing to unprimed cells, TbEVs, and Ag stimulated cells $(p=0.0313)$ (Figure $8 \mathrm{C}$ ). Parasite $\mathrm{Ag}$ and TbEVs caused a high expansion of FoxP3 ${ }^{+} \mathrm{CD}^{+}$(Figure 8D) and FoxP3 ${ }^{+} \mathrm{CD}_{2} 5^{+} \mathrm{CD}^{+} \mathrm{T}$ cells $(p=0.0313$ ) (Figure $8 \mathrm{~A})$ in comparison to unprimed cells.

Stimulation of PBMC by ConA led to a significant expansion $(p=0.0313)$ of $\mathrm{CD} 4^{+} \mathrm{T}$ cell subset (Figure 8B). On the other hand, parasites, TbEVs or Ag did not seem to affect the $\mathrm{CD}^{+}{ }^{\text {(FoxP3 }}{ }^{-} \mathrm{CD} 25^{-}$) $\mathrm{T}$ cell subset.

TbEVs and parasites promoted a higher fluorescence intensity of CD25-labeled cells when compared with unprimed lymphocytes $(p=0.0313)$. Furthermore, T. $b$. brucei parasites induced a higher expression of CD25 molecules in comparison to TbEVs and Ag stimulated cells $(p=0.0313)$. Significant overexpression of intracellular FoxP3 molecules was also found in $\mathrm{CD}^{+} \mathrm{T}$ cells after stimulation with TbEVs or Ag $(p=0.0331)$.

These results indicated that $\mathrm{TbEVs}$ and parasite $\mathrm{Ag}$ favoured expansion of regulatory $\mathrm{CD}^{+} \mathrm{T}$ cell subset $\left(\mathrm{FoxP}^{+} \mathrm{CD}^{+} 5^{+} \mathrm{CD}^{+} \mathrm{CD}^{+}, \mathrm{T}\right.$ reg cells) and $\mathrm{FoxP}^{+} \mathrm{CD}^{+} \mathrm{T}$ cells. Moreover, T. b. brucei parasites enhanced the frequency of $\mathrm{CD} 25^{+} \mathrm{CD} 4^{+} \mathrm{T}$ cells. Among $\mathrm{CD} 4^{+} \mathrm{T}$ cells, the overexpression of $\alpha$-chain of IL2-receptor (CD25) was induced by parasites and TbEVs, and the increased expression of FoxP3 was elicited by TbEVs and Ag.

3.7. TbEVs Direct the Expansion of Effector $\mathrm{CD}^{+} \mathrm{T}$ Cells and $\mathrm{CD} 8^{+} \mathrm{T}$ Cells Expressing FoxP3 ${ }^{+}$ Phenotype and Increase Surface CD25 and Intracellular FoxP3 Molecules

$\mathrm{CD}^{+} \mathrm{T}$ cell subsets were examined by estimating the frequency of $\mathrm{CD} 88^{+} \mathrm{T}$ cells expressing CD25 in mononuclear blood cells exposed to parasites and stimulated by TbEVs or parasite Ag (Figure 9). The expression of FoxP3 was evaluated in stimulated cells. Furthermore, the potential of these cells to recognize IL-2 and regulate the cell 
immune activity was indirectly assessed by the density of surface CD25 and intracellular FoxP3 molecules.

A

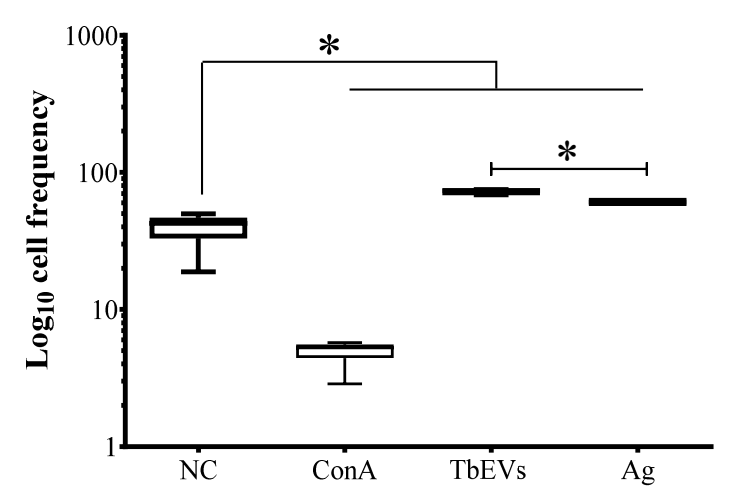

C

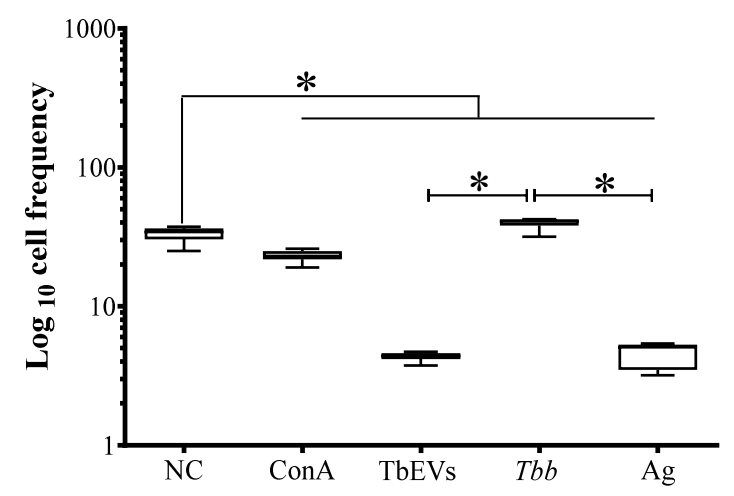

B

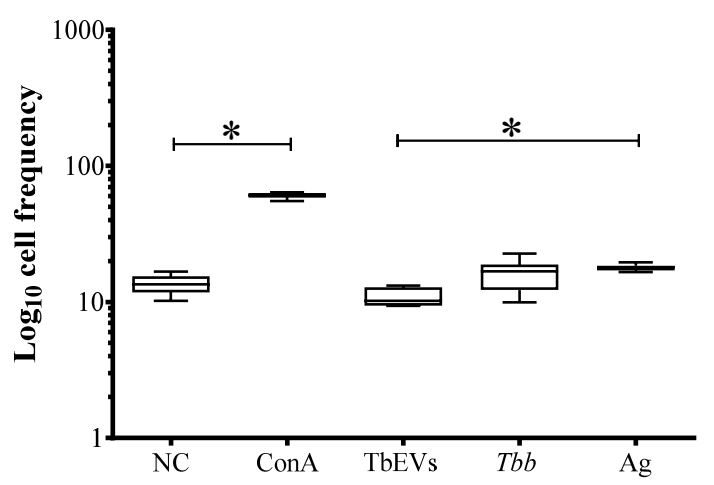

D

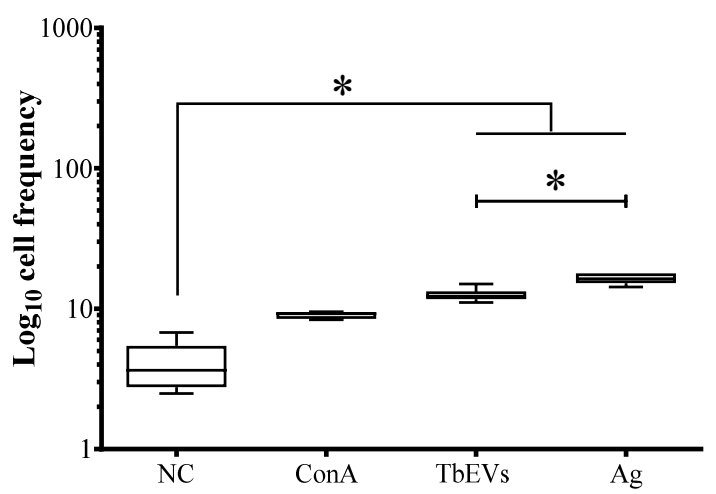

Figure 8. Differentiation of $\mathrm{CD}_{2} 5^{+}$and FoxP3 ${ }^{+} \mathrm{CD} 4^{+} \mathrm{T}$ cell subsets induced by T. b. brucei EVs. CD4 ${ }^{+}$cell fraction exposed to T. $b$. brucei parasites (Tbb), stimulated by Ag, TbbEVs, and ConA, and unprimed cells (negative control, NC) were labelled with CD3, CD25 and FoxP3 monoclonal antibodies and evaluated by flow cytometry. $\mathrm{CD}^{+}$cells were gated and the frequency of $\mathrm{CD}_{2} 5^{+} \mathrm{FoxP}^{+}$(A), $\mathrm{CD}^{-} 5^{-} \mathrm{FoxP}^{-}$(B) $\mathrm{CD}^{+} 5^{+} \mathrm{FoxP}^{-}$(C) and $\mathrm{CD}^{-} 5^{-} \mathrm{FoxP}^{+}$(D) cell subsets were estimated. In consequence of the low levels of $\mathrm{CD}^{+}$cells, the frequency and density of FoxP3 were not considered in T. $b$. brucei exposed-PBMC. Results of three independent experiments $(n=18)$ performed in duplicate are represented by whiskered box-plot, median, minimum, and maximum values. The non-parametric Wilcoxon matched-pair signed-rank test was used for statistical comparisons. ${ }^{*}(p<0.05)$ indicated significant differences.

When compared to unprimed $\mathrm{CD}^{+} \mathrm{CD}^{+}$cells, it was observed that ConA stimulation caused a significant high frequency of $\mathrm{CD} 8^{+} \mathrm{T}$ cell subsets expressing $\mathrm{CD} 25^{+}$and FoxP3 $^{+}\left(p_{\mathrm{CD} 25}{ }^{+} \mathrm{FoxP}^{+}=0.0313\right.$, Figure $9 \mathrm{~A} ; p_{\mathrm{CD} 25}{ }^{+}=0.0078$, Figure $\left.9 \mathrm{C}\right)$ as well as CD8 ${ }^{+}$ $\left(\mathrm{CD}^{-} 5^{-}\right.$FoxP3 $\left.^{-}\right)$T cells $(p=0.0516$, Figure 9B). Cells stimulated by TbEVs $(p=0.0156)$ showed significant high frequencies of $\mathrm{CD}^{2} 5^{+} \mathrm{FoxP}^{+} \mathrm{CD} 8^{+} \mathrm{T}$ cells (Figure 9A).

TbEVs and Ag induced a significant expansion of $\mathrm{CD}^{+}\left(\mathrm{CD} 25^{-} \mathrm{FoxP}^{-}\right) \mathrm{T}$ cell subset $(p=0.0156)$ and promoted the retraction of $\mathrm{CD}_{2} 5^{-} \mathrm{FoxP}^{+} \mathrm{CD}^{+} \mathrm{T}$ cell subset $(p=0.0313)$ (Figure 9B). However, when compared to unprimed cells, T. b. brucei parasites caused a significant restrain of $\mathrm{CD} 8^{+} \mathrm{T}$ cells.

$\mathrm{CD} 8^{+} \mathrm{T}$ cells exposed to T. b. brucei parasites or stimulated by ConA, TbEVs, and parasite Ag showed a significant increase of CD25 molecules $(p=0.0313)$ when comparing with unprimed cells. Furthermore, FoxP3 fluorescent intensity also increased in CD8 ${ }^{+} \mathrm{T}$ cells stimulated by TbEVs $(p=0.0313)$.

Altogether the results indicated that TbEVs mainly triggered the expansion of effector $\mathrm{CD} 8^{+} \mathrm{T}$ cells and $\mathrm{CD} 8^{+} \mathrm{T}$ cell subsets expressing FoxP3 associated with a higher density 
of FoxP3 molecules. The overexpression of $\alpha$-chain of IL2-receptor (CD25) induced by parasites can be mainly associated with the expansion of $\mathrm{CD} 25^{+} \mathrm{CD} 8^{+} \mathrm{T}$ cell subset.
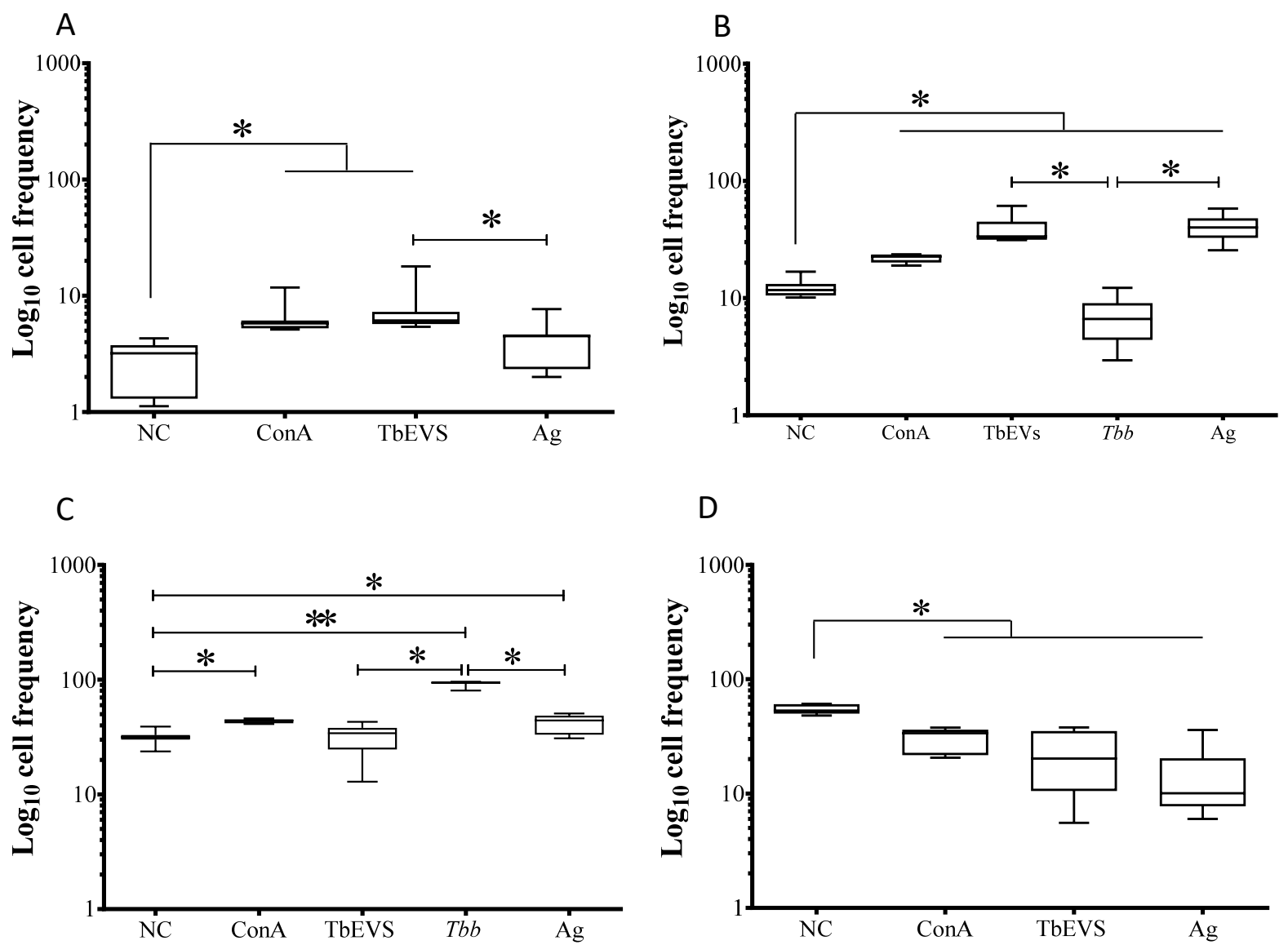

Figure 9. $\mathrm{CD}^{+} 5^{+}$and FoxP3 ${ }^{+} \mathrm{CD}^{+} \mathrm{T}$ cell subsets induced by T. $b$. brucei EVs. Mouse lymphocytes exposed to T. $b$. brucei parasites $(\mathrm{Tbb})$, stimulated by Ag, TbEVs, and ConA, and unprimed cells (negative control, NC) were labelled with CD3, CD25 and FoxP3 monoclonal antibodies and evaluated by flow cytometry. CD3 ${ }^{+}$cells were gated and the frequency of $\mathrm{CD}_{2} 5^{+} \mathrm{FoxP3}^{+}(\mathbf{A}), \mathrm{CD}_{2} 5^{-} \mathrm{FoxP}^{-}(\mathbf{B}), \mathrm{CD}^{2} 5^{+} \mathrm{FoxP}^{-}(\mathbf{C})$, and $\mathrm{CD}^{-} 5^{-} \mathrm{FoxP}^{+}$(D) cell subsets were estimated. In consequence of the low levels of $\mathrm{CD}^{+}$cells, the frequency and density of FoxP3 were not considered in T. $b$. brucei exposed-PBMC. Results of $(n=6)$ at least three independent experiments performed in duplicate are represented by whiskers box-plot, median, minimum and maximum values. The non-parametric Wilcoxon matched-pair signed-rank test was used for statistical comparisons. ${ }^{*}(p<0.05)$ and ${ }^{* *}(p<0.01)$ indicate significant differences.

\subsection{TbEVs and Parasite Ag Triggered Related Influence on the Phenotype of BALB/c Mice T Cells}

PCA analysis of $\mathrm{CD} 4^{+}$and $\mathrm{CD} 8^{+} \mathrm{T}$ cells indicated a positive correlation between the effect of TbEVs and parasite Ag on T cells (Figure 10A), which contrasted with T. b. brucei effects. These results were confirmed by cluster analysis, which showed the effects of Ag and TbEVs grouped in cluster 3 . On the other hand, the influence of parasites in T cells was grouped at cluster 1. Furthermore, ConA stimulation outcomes were localized in cluster 2 and the intrinsic activity of unprimed T cells were mainly within cluster 3 (Figure 10B). Overall, the effect of TbEVs on BALB/c mice T cells seemed to be similar to cell stimulation caused by parasite Ag and slightly different of unprimed cells, but completely different from T. b. brucei parasites. 
A

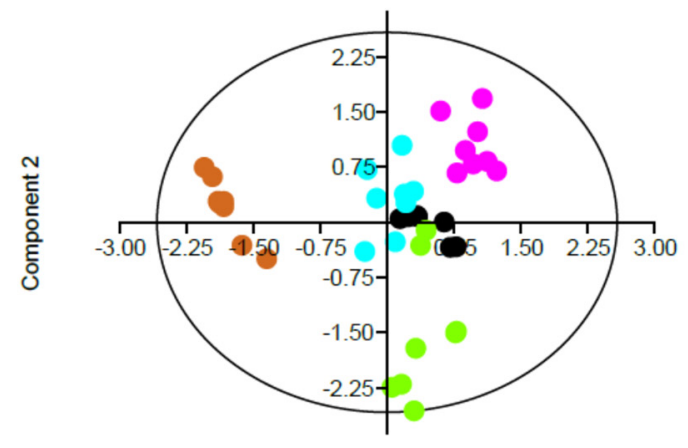

B

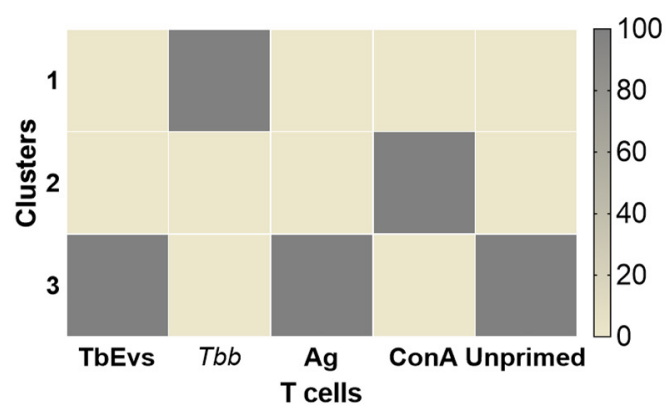

Component 1

Figure 10. The effect TbEVs on mice T cells. Relationship between the effect of TbEVs (black dots), parasite Ag (blue dots), ConA (pink dots) and viable T. b. brucei trypomastigotes (brown dots) in $\mathrm{CD}^{+}$cells, including frequency of $\mathrm{CD}^{2} 5^{+}, \mathrm{FoxP}^{+}$, and $\mathrm{CD} 25^{+} \mathrm{FoxP}^{+}$subsets and the density of $\mathrm{CD} 3, \mathrm{CD} 25$, and FoxP3 molecules are represented by a variable correlation plot (A). In consequence of the low levels of $\mathrm{CD}^{+}$cells, the frequency and density of FoxP3 were not considered in T. b. brucei exposed-PBMC. Unprimed cells (negative control) are indicated by green dots. Cluster distribution of the effect TbEVs, parasite $\mathrm{Ag}$, ConA, and trypomastigotes $(\mathrm{Tb} b)$ on $\mathrm{T}$ cells compared with unprimed cells $(\mathrm{NC})$ are represented by the heat map (B).

\section{Discussion}

African trypanosomes have been extensively studied since they are responsible for severe diseases in both medical and veterinary contexts. To survive, this extracellular protozoan affords several mechanisms that use to evade the mammals' immune system. Also, to ensure the completion of its life cycle, the parasite needs to avoid host mortality during the hemolymphatic phase. Therefore, a balance between infection level (parasitemia) and the intensity of the inflammatory immune response must be achieved in the host. Since safe and efficient anti-trypanosomal drugs and vaccines are lacking, many are the studies performed to understand the mechanisms associated with the host immune response direct against T. brucei infection. Although different approaches were applied, and numerous findings reported, some questions remain unanswered, and some mechanisms are not entirely understood or still controversial.

Since EVs released by eucaryotic cells seem to play a role in intercellular communication, interfering with several cellular processes, such as the activation of microbicide processes and generation of immune mediators by changing gene expression and affecting signalling pathways the potential of trypomastigotes derived EVs in influencing the immune activity of innate and adaptive immune cells was explored. Findings of the current study indicate that TbEVs shed by trypomastigotes is enriched in proteins and are a heterogeneous population of spherical vesicles mainly constituted by smaller $(<0.17 \mathrm{~nm})$ and biggest $(>0.17 \mathrm{~nm}) \mathrm{EVs}$, which is in line with previous findings [12].

Since the expansion in different organs and tissues of the $M \Phi$ population, as is the case of the liver, spleen, and the bone marrow was described in T. brucei infected mice, the intercommunication of TbEVs with innate immune cells were examined. It is reported that inducible nitric oxide synthase (iNOS) peaked six days post-infection and that oxidized L-arginine generates L-citrulline and NO [15]. In the current study, TbEVs trigger mouse $\mathrm{M} \Phi$ to produce $\mathrm{NO}$ as well as T. brucei cultured parasites, suggesting a role for TbEVs at the early stage of sleeping sickness. NO is a highly regulated effector molecule, which participates in several physiological and immune processes and can inactivate pathogens including T. brucei parasites [15]. However, high NO levels can be a disadvantage to the host, given the large spectra of cell disorders that are associated with NO activity. In sleeping sickness, the persistence of M1-M $\Phi$ is related to anaemia and systemic immune response [16-19]. 
To counteract the possible harmful effect of NO in the host and perpetuate parasite replication, African trypanosomes induce the differentiation of M2-M $\Phi$. L-Arginine can be hydrolyzed by arginase, generating ornithine, urea, proline and polyamines [20]. A previous study performed in T. b. brucei-infected mice indicates that M1-M $\Phi$ predominate in the early stage of infection while M2-M $\Phi$ prevail at a later infection stage (1-4 weeks) [18]. In the current study was found that TbEVs and cultured parasites induced urea and NO production by mouse $M \Phi$. These findings reinforce the role of TbEVs in the early stage of infection as a $M \Phi$ modulator. By inducing the differentiation of mouse $\mathrm{M} \Phi$ expressing M1 and M2 phenotypes, TbEVs seem to strengthen parasite activity in sustaining a balance between pro-inflammatory and anti-inflammatory responses. Moreover, by simultaneously ensuring the supported production of polyamines, which are essential nutrients for parasite survival and replication $[7,21]$, TbEVs can facilitate the establishment of a chronic infection. The kinesin-1 heavy chain (TbKHC-1) released by African trypanosomes has been described as an activator of the arginine pathway, leading to the production of polyamines [7]. Taking into account the above considerations, TbKHC-1 may form part of TbEVs' cargo.

Contrary to T. b. brucei parasites that cause a marked reduction in the frequency of $\mathrm{MHCI}^{+}$and $\mathrm{MHCII}^{+} \mathrm{M} \Phi$, affecting the recognition of parasite antigens by Tlymphocytes and compromising the adaptive immune response, $\mathrm{TbEVs}^{+}$induce differentiation of $\mathrm{MHCI}^{+}$ and $\mathrm{MHCII}^{+} \mathrm{M} \Phi$ and double-positive $\mathrm{M} \Phi\left(\mathrm{MHCI}^{+} \mathrm{MHCII}^{+}\right)$, indicating that these cells can establish a link with acquired immunity by presenting parasite antigens to helper and cytotoxic T cells. Even so, the density of MHCI and MHCII molecules on the membrane surface of $M \Phi$ remained similar to resting $M \Phi$. Though not fully understood similar inhibition of MHC expression avoiding antigen presentation was mentioned in a study carried out on T. cruzi, which is an intracellular parasite responsible for Chagas' disease or American trypanosomiasis [22]. Therefore, TbEVs that appear to exert an action contrary to the parasite may cause the activation of adaptive immunity at least to some point, activating both $\mathrm{CD} 4^{+}$and $\mathrm{CD} 8^{+} \mathrm{T}$ cells.

During the course of infection, T. brucei releases the stumpy induction factor (TSIF) that has been associated with the impairment of $\mathrm{T}$ cell proliferation [23]. A previous study performed in patients infected with T. $b$. gambiense has shown that T cells were considerably lower when compared with controls [24]. Thus, considering the high importance of cellular activation in orchestrating an integrated host immune response against sleeping sickness, the communication established by TbEVs on $\mathrm{T}$ cell expansion was also examined. In agreement with previous findings, a marked reduction of both $\mathrm{CD}^{+} \mathrm{CD}^{+}$and $\mathrm{CD}^{+} \mathrm{CD}^{+} \mathrm{T}$ cells caused by T. b. brucei parasites was found in the current study. However, TbEVs favour the expansion of $\mathrm{CD}^{+} \mathrm{T}$ cell subpopulation and induce the increase of $\mathrm{CD} 3$ expression in both $\mathrm{CD}^{+}$and $\mathrm{CD} 8^{+}$subsets $\left(\mathrm{CD} 3^{\text {hi }} \mathrm{CD}^{+}\right.$and $\mathrm{CD} 3^{\text {hi }} \mathrm{CD} 8^{+} \mathrm{T}$ cells). $\mathrm{CD} 3$ complex is a $\mathrm{T}$ cell co-receptor responsible for intracellular signalling. Altogether, these findings indicate that, contrary to T. b. brucei, TbEVs may have the necessary conditions to stimulate T cells. However, in a previous study, Boda and colleagues [25] reported that effector CD8 ${ }^{+} \mathrm{T}$ cells were significantly lower in patients with African trypanosomiasis which corroborates our findings.

In the current study, T. b. brucei parasites induce the expansion of $\mathrm{CD}^{+}$and $\mathrm{CD} 8^{+}$ $\mathrm{T}$ cell subpopulations expressing a CD25 phenotype and favour the expression of CD25 molecules (CD25 ${ }^{\text {hi }} \mathrm{CD} 4^{+}$and $\mathrm{CD} 25^{\mathrm{hi}} \mathrm{CD} 8^{+} \mathrm{T}$ cells). CD25 is the $\alpha$ chain of the IL-2 receptor, which is expressed by regulatory T (Treg) cells. CD25 is required for interleukin (IL)-2 signalling that mediates $\mathrm{T}$ cell activation and proliferation. To become fully activated, CD8 ${ }^{+}$ $\mathrm{T}$ cells require the help of $\mathrm{CD}^{+} \mathrm{T}$ cells mediated by IL-2. However, Kalia et al. [26] have found that $\mathrm{CD} 25^{\mathrm{hi}} \mathrm{CD} 8{ }^{+} \mathrm{T}$ cells can perceive proliferation signals (IL-2) and differentiate into short-lived effector cells and Olson et al. [27] reported that lymphocyte triggering factor (TLTF) released by T. b. brucei specifically elicit $\mathrm{CD}^{+} \mathrm{T}$ cells to generate IFN- $\gamma$. Moreover, it was reported that activated $\mathrm{CD} 4^{+} \mathrm{T}$ cells secrete IFN- $\gamma$ and is recognised that this cytokine functions as a T. b. brucei growth factor [28]. Thus, T. b. brucei parasites may favour the expansion of $\mathrm{CD} 25^{+} \mathrm{T}$ cells to ensure their survival. 
FoxP3 nuclear factor is a regulator of gene expression that suppresses the function of NFAT and NF- $\mathrm{kB}$ nuclear factors, avoiding the expression of pro-inflammatory cytokine genes, including IL-2. CD4 ${ }^{+}$Treg cells which constitutively express FoxP3 can suppress leukocyte effector activity, contributing to the maintenance of immune homeostasis. These regulatory cells also exhibit a high expression of CD25 molecules. In African trypanosomiasis, the expansion of Treg cells seems to occur from the parasite establishment to the chronic stage, being associated with parasite tolerance (reviewed in [29]) and in trypanotolerant C57BL/ 6 mice, the expansion of $\mathrm{CD}_{2} 5^{+} \mathrm{FoxP}^{+} \mathrm{CD}^{+} \mathrm{T}$ cell subset was demonstrated after the first peak of parasitemia [30]. On the other hand, the lack of expansion of Treg cells is associated with tissue damage and impaired survival of infected mice [31]. In the current study, TbEVs promote the expansion of $\mathrm{CD}^{+}$and $\mathrm{CD} 8^{+}$Treg cells and $\mathrm{FoxP}^{+} \mathrm{CD}^{+} \mathrm{T}$ cell subset. According to Zelenay et al. [32], $\mathrm{CD}^{+} \mathrm{T}$ cells expressing FoxP3 ${ }^{+}$phenotype are committed Treg cells able to regain CD25 expression. Thus, TbEVs seem to induce the differentiation of $\mathrm{CD}^{+}$and $\mathrm{CD} 8^{+}$Treg cells and unconventional $\mathrm{CD} 4^{+}$Treg cells. In previous studies, it was reported that unconventional-Treg cells also can exert regulatory functions [33]. During chronic parasite infection, uncontrolled inflammation is one of the most clinical features noticed that can become lethal if not controlled by Treg cells [34,35]. Therefore, during infection TbEVs can lead to the establishment of a pool of T cells with a regulatory phenotype able to balance excessive inflammation.

Altogether, these findings indicate that T. b. brucei parasites can activate the metabolization of arginine by $\mathrm{M} \Phi$ and [36] modulate $\mathrm{T}$ cells, ensuring the production of polyamines and IFN- $\gamma$, both critical for parasite survival. At the same time, this parasite avoids antigen presentation by $\mathrm{M} \Phi$ and T cells activation.

However, the findings of the present study place in evidence that TbEVs can establish direct communication with cells of innate and adaptive immunity, and the effect of TbEVs on these cells is different from the parasite itself. TbEVs can elicit parasite antigenic presentation to $\mathrm{CD} 4^{+}$and $\mathrm{CD} 8^{+} \mathrm{T}$ cells possible leading to the activation of the cellular immune response in addition to the bidirectional activation of mouse $M \Phi$, contributing to the release of factors essential to parasite growth and, also, to parasite destruction. Moreover, TbEVs also seems to have a direct effect on $\mathrm{CD}^{+} \mathrm{T}$ lymphocytes, triggering the expression of $\mathrm{T}$ cell co-receptors, which are key players in intracellular signalling. The expression of the nuclear factor FoxP3 was also stimulated by TbEVs, guiding the differentiation of $\mathrm{CD}^{+}$ and $\mathrm{CD} 8^{+}$Treg cells. imposing regulation on host inflammatory immune response which is a hallmark of sleeping sickness. Since an unbalanced inflammatory response against the parasite can become lethal to the host, the role of Treg cells in protecting from collateral tissue damage is crucial. On the other hand, TbEVs induced the differentiation of effector $\mathrm{CD}^{+} \mathrm{T}$ cells and drive the overexpression of FoxP3 molecules in $\mathrm{CD}^{+} \mathrm{T}$ cells which are involved in maintaining immune homeostasis. Therefore, parasites and TbEVs seem to display complementary effects in the host immune response that can ensure parasite survival, delaying disease severity and the eventual death of the host. Furthermore, TbEVs represent a source of biomarkers that can open new avenues for a better diagnosis of sleeping sickness and the development of prophylactic measures to control the disease caused by T. brucei in Subsaharan Africa.

Supplementary Materials: The following are available online at https://www.mdpi.com/article/ 10.3390/biomedicines9081056/s1, Supplementary Figures S1 and S2, Supplementary videos: https: //drive.google.com/file/d/0B7h7gNscHF0TWmZNR19sZWpQUDg/view?usp=sharing. Supplementary Video S1. Blood infected with T. b. brucei. Blood of infected BALB/c mice was directly observed at $\times 100$ magnification under an optical microscope and video recorded. https: // drive.google.com/file/d/1oET-8Ehh3mLJIz6FoFlCoO_qEac4pwPV/view?usp=sharing. Supplementary Video S2. T. b. brucei blood forms. Parasites were directly observed in the blood of infected $\mathrm{BALB} / \mathrm{c}$ mice at $\times 400$ magnification under an optical microscope and video recorded.

Author Contributions: Conceptualization, formal analysis, supervision, G.S.-G.; investigation, T.D.-G. and J.P.-M.; formal analysis, writing — review and editing, G.A.-P.; resource, W.A. and T.N.; resources, writing—review and editing, A.V.-B.; writing—review and editing, P.M.-G., Á.G. and 
I.P.d.F. resources-supervision, M.S.-S. All authors have read and agreed to the published version of the manuscript.

Funding: This study was supported by FCT_Foundation for Science and Technology, I.P., through research grant PTDC/CVT-CVT/28908/2017 and by national funds within the scope of Centro de Investigação Interdisciplinar em Sanidade Animal (CIISA, UIDB/00276/2020) and Global Health and Tropical Medicine (GHTM, UID/04413/2020).

Institutional Review Board Statement: This study was approved by the IHMT's ethics committee and the Portuguese National Authority for Animal Health (DGAV—Direção Geral de Alimentação e Veterinária)-Ref. 0421/000/000/2020, 23 September 2020.

Informed Consent Statement: Not applicable.

Data Availability Statement: The data presented in this study are available on request from the corresponding author (G.S.-G.). The data are not publicly available due to confidentiality.

Conflicts of Interest: The authors declare no conflict of interest.

\section{References}

1. Barrett, M.P.; Burchmore, S.; Stich, A.; Lazzari, J.; Frasch, A.C.; Cazzulo, J.; Krishna, S. The trypanosomiases. Lancet 2003, 362, 1469-1480. [CrossRef]

2. Vincendeau, P.; Bouteille, B. Immunology and immunopathology of African trypanosomiasis. An. Acad. Bras. Cienc. 2006, 78, 645-665. [CrossRef] [PubMed]

3. Lundkvist, B.; Kristensso, N.K.; Bentivoglio, M. Why trypanosomes cause sleeping sickness. Physiology 2004, 19, 198-206. [CrossRef] [PubMed]

4. Cnops, J.; Kauffmann, F.; De Trez, C.; Baltz, T.; Keirsse, J.; Radwanska, M.; Muraille, E.; Magez, S. Maintenance of B cells during chronic murine Trypanosoma brucei gambiense infection. Parasite Immunol. 2016, 38, 642-647. [CrossRef]

5. Paulnock, M.; Freeman, E.; Mansfield, M. Modulation of innate immunity by African Trypanosomes. Parasitology 2010, 137, 2051-2063. [CrossRef]

6. Baral, T. Immunobiology of African Trypanosomes: Need of alternative interventions. J. Biomed. Biotechnol. $2010,24,389153$. [CrossRef]

7. Salmon, D.; Vanwalleghem, G.; Morias, Y.; Denoeud, J.; Krumbholz, C.; Lhomme, F.; Bachmaier, S.; Kador, M.; Gossmann, J.; Dias, F.B.S.; et al. Adenylate cyclases of Trypanosoma brucei inhibit the innate immune response of the host. Science 2012, 337, 463-466. [CrossRef]

8. De Muylder, G.; Daulouede, S.; Lecordier, L.; Uzureau, P.; Morias, Y.; Van Den Abbeele, J.; Caljon, G.; Herin, M.; Holzmuller, P.; Semballa, S.; et al. A Trypanosoma brucei kinesin heavy chain promotes parasite growth by triggering host arginase activity. PLoS Pathog. 2013, 9-14, e1003731. [CrossRef]

9. Namangala, B. Contribution of innate immune responses towards resistance to African Trypanosome infections. Scand. J. Immunol. 2012, 75, 5-15. [CrossRef]

10. Pays, E.; Vanhollebeke, B. Human innate immunity against African trypanosomes. Curr. Opin. Immunol. 2009, 21, 493-498. [CrossRef]

11. Stoorvogel, W.; Kleijmeer, M.; Geuze, H.; Raposo, G. The biogenesis and functions of exosomes. Traffic 2002, 3, 321-330. [CrossRef]

12. Marcilla, A.; Martin-Jaular, L.; Trelis, M.; Menezes-Neto, A.; Osuna, A.; Bernal, D.; Fernandez-Becerra, C.; Almeida, I.C.; Del Portillo, H.A. Extracellular vesicles in parasitic diseases. J. Extracell. Vesicles 2014, 3, 3402. [CrossRef] [PubMed]

13. Szempruch, J.; Sykes, S.; Kieft, R.; Dennison, L.; Becker, A.; Gartrell, A. Extracellular vesicles from Trypanosoma brucei mediate virulence factor transfer and cause host anemia. Cell 2016, 164, 246-257. [CrossRef] [PubMed]

14. Lanham, S.M.; Godfrey, D.G. Isolation of salivarian trypanosomes from man and other mammals using deae-cellulose. Exp. Parasitol. 1970, 28, 521-534. [CrossRef]

15. Santos-Gomes, G.M.; Rodrigues, A.; Teixeira, F.; Carreira, J.; Alexandre-Pires, G.; Carvalho, S.; Santos-Mateus, D.; Martins, C.; Vale-Gato, I.; Marques, C.; et al. Immunization with the Leishmania infantum recombinant cyclophilin protein 1 confers partial protection to subsequent parasite infection and generates specific memory T cells. Vaccine 2014, 5, 1247-1253. [CrossRef] [PubMed]

16. Gobert, A.P.; Daulouede, S.; Lepoivre, M.; Boucher, J.L.; Bouteille, B.; Buguet, A.; Cespuglio, R.; Veyret, B.; Vincendeau, P. L-arginine availability modulates local nitric oxide production and parasite killing in experimental trypanosomiasis. Infect. Immun. 2000, 68, 4653-4657. [CrossRef] [PubMed]

17. Bertero, M.T.; Caligaris-Cappio, F. Anemia of chronic disorders in systemic autoimmune diseases. Haematologica 1997, 82, 375-381.

18. Davies, G.; Hagen, O. Systemic inflammatory response syndrome. Br. J. Surg. 1997, 84, 920-935. [CrossRef]

19. Stijemans, B.; Guilliams, M.; Raes, G.; Beschin, A.; Magez, S.; De Baetselier, P. African trypanosomosis: From immune escape and in immunopathology to immune intervention. Vet. Parasitol. 2007, 148, 3-13. [CrossRef] 
20. Stijlemans, B.; Radwanska, M.; De Trez, C.; Magez, S. African trypanosomes undermine humoral responses and vaccine development: Link with inflammatory responses? Front. Immunol. 2017, 8, 14. [CrossRef]

21. Gordon, S.; Martinez, F.O. Alternative activation of macrophages: Mechanism and functions. Immunity 2010, 32, 593-604. [CrossRef]

22. Lott, K.; Zhu, L.; Fisk, C.; Tomasello, L.; Read, K. Functional interplay between protein arginine methyltransferases in Trypanosoma brucei. Microbiol. Open 2014, 3, 595-609. [CrossRef] [PubMed]

23. Camargo, R.; Faria, L.; Kloss, A.; Favali, F.; Kuckelkorn, U.; Kloetzel, P.; De Sa, M.; Lima, D. Trypanosoma cruzi infection down-modulates the immunoproteasome biosynthesis and the MHC class I cell surface expression in hela cells. PLoS ONE 2014, 9, e95977.

24. Gomez-Rodriguez, J.; Stijlemans, B.; De Muylder, G.; Korf, H.; Brys, L.; Berberof, M.; Darji, A.; Pays, E.; De Baetselier, P.; Beschin, A. Identification of a parasitic immunomodulatory protein triggering the development of suppressive m1 macrophages during african trypanosomiasis. J. Infect. Dis. 2009, 200, 1849-1860. [CrossRef]

25. Lejon, V.; Ngoyi, D.M.; Kestens, L.; Boel, L.; Barbe, B.; Betu, V.K.; Van Griensven, J.; Bottieau, E.; Tamfum, J.J.M.; Jacobs, J.; et al. Gambiense human african trypanosomiasis and immunological memory: Effect on phenotypic lymphocyte profiles and humoral immunity. PLoS Pathog. 2014, 10, 10. [CrossRef] [PubMed]

26. Boda, C.; Courtioux, B.; Roques, P.; Pervieux, L.; Vatunga, G.; Josenando, T.; Roger, C.; Bouteille, A.; Jauberteau, M.-O.; Bisser, S. Immunophenotypic lymphocyte profiles in human african trypanosomiasis. PLoS ONE 2009, 8, e6184. [CrossRef]

27. Kalia, V.; Sarkar, S.; Subramaniam, S.W.; Nicholas Haining, K.; Smith, A.; Ahmed, R. Prolonged Interleukin-2R $\alpha$ Expression on Virus-Specific CD8 ${ }^{+}$T Cells Favors Terminal-Effector Differentiation In Vivo. Immunity 2009, 32, 91-103. [CrossRef]

28. Olsson, T.; Bakhiet, M.; Hoijeberg, B.; Ljungdahl, A.; Edlund, C.; Andersson, G.; Ekre, H.P.; Fung-Leung, W.P.; Mak, T.; Wigzell, H.; et al. CD8 is critically involved in lymphocyte activation by a T. brucei brucei-released molecule. Cell 1993, 72, 715-727. [CrossRef]

29. Liu, G.; Sun, L.; Wu, H.; Zhang, S.; Huan, X.; Xu, J.; Zhang, Q.; Zhou, H.; Shi, Q. Distinct contributions of CD4 (+) and CD8 (+) t cells to pathogenesis of Trypanosoma brucei infection in the context of gamma interferon and interleukin-10. Infect. Immun. 2015, 83, 2785-2795. [CrossRef]

30. Adalid-Peralta, L.; Fragoso, G.; Fleury, A.; Sciutto, E. Mechanisms underlying the induction of regulatory T cells and its relevance in the adaptive immune response in parasitic infections. Int. J. Biol. Sci. 2011, 7, 1412-1426. [CrossRef] [PubMed]

31. Guilliams, M.; Oldenhove, G.; Noel, W.; Herin, M.; Brys, L.; Loi, P.; Famand, V.; Moser, M.; De Baetselier, P.; Beschin, A. African trypanosomiasis: Naturally occurring regulatory $t$ cells favor trypanotolerance by limiting pathology associated with sustained type 1 inflammation. J. Immunol. 2007, 179, 2748-2757. [CrossRef] [PubMed]

32. Guilliams, M.; Bosschaerts, T.; Herin, M.; Hunig, T.; Loi, P.; Flamand, V.; De Baetselier, P.; Beschin, A. Experimental expansion of the regulatory $t$ cell population increases resistance to african trypanosomiasis. J. Infect. Dis. 2008, 198, 781-791. [CrossRef]

33. Zelenay, S.; Lopes-Carvalho, T.; Caramalho, I.; Moraes-Fontes, M.F.; Rebelo, M.; Demengeot, J. Foxp3(+) CD25(-) CD4 T cells constitute a reservoir of committed regulatory cells that regain cd25 expression upon homeostatic expansion. Proc. Natl. Acad. Sci. USA 2005, 102, 4091-4096. [CrossRef] [PubMed]

34. Angerami, M.; Suarez, G.; Vecchione, M.; Laufer, N.; Ameri, D.; Ben, G.; Perez, H.; Sued, O.; Salomón, H.; Quiroga, M. Expansion of CD25-Negative Forkhead Box P3-Positive T cells during HIV and Mycobacterium tuberculosis infection. Front. Immunol. 2017, 9, 528. [CrossRef] [PubMed]

35. Vignali, D.A.A.; Collison, L.W.; Workman, C.J. How regulatory t cells work. Nat. Rev. Immunol. 2008, 8, 523-532. [CrossRef]

36. Corthay, A. How do regulatory T cells work? Scand. J. Immunol. 2009, 70, 326-336. [CrossRef] 